\title{
Key Features of Common Lygus Species in the Central San Joaquin Valley
}

This handout should be used in conjunction with the detailed explanations and descriptions in

A Field Key to the Most Common Lygus Species Found in Agronomic Crops of the Central San Joaquin Valley of California

(UC ANR Publication 8104 at http://anrcatalog.ucdavis.edu or Lygus.uckac.edu)

The characteristics shown here best describe males of each species.

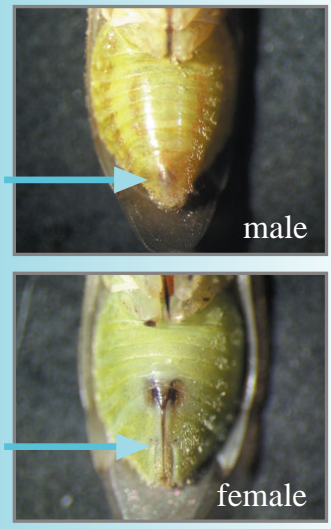

These species all have a smooth frons and yellow or green hind tibia. If your specimen does not exhibit these features, it is NOT one of the species identified in this publication.

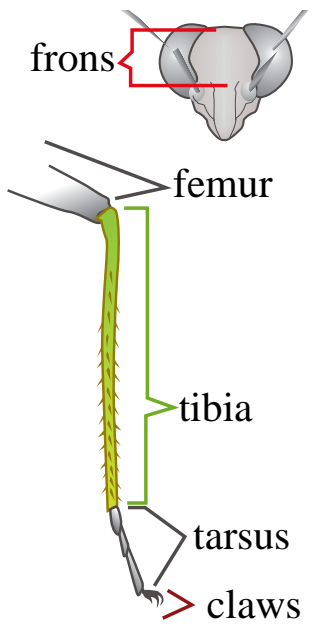

Publication 8105 is a "quick guide" that can be removed from the center of Publication 8104 and used independently once the user is familiar with key characteristics for distinguishing between species.

Examination of three characteristics will usually allow you to determine whether the specimen is Lygus hesperus or Lygus elisus. The characteristics are observed by examining the pronotum, the propleura, and the wing membrane. To confirm the initial identification based upon the three most reliable characteristics, examine the shape of the scutellum and the relative length of the rostrum.

\section{Western Tarnished Plant Bug Lygus hesperus (Knight)}
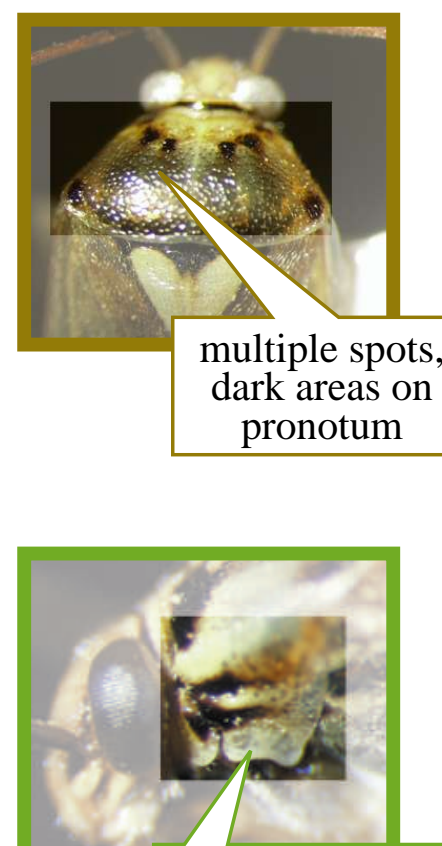

spot, line, or multiple spots or lines on propleura
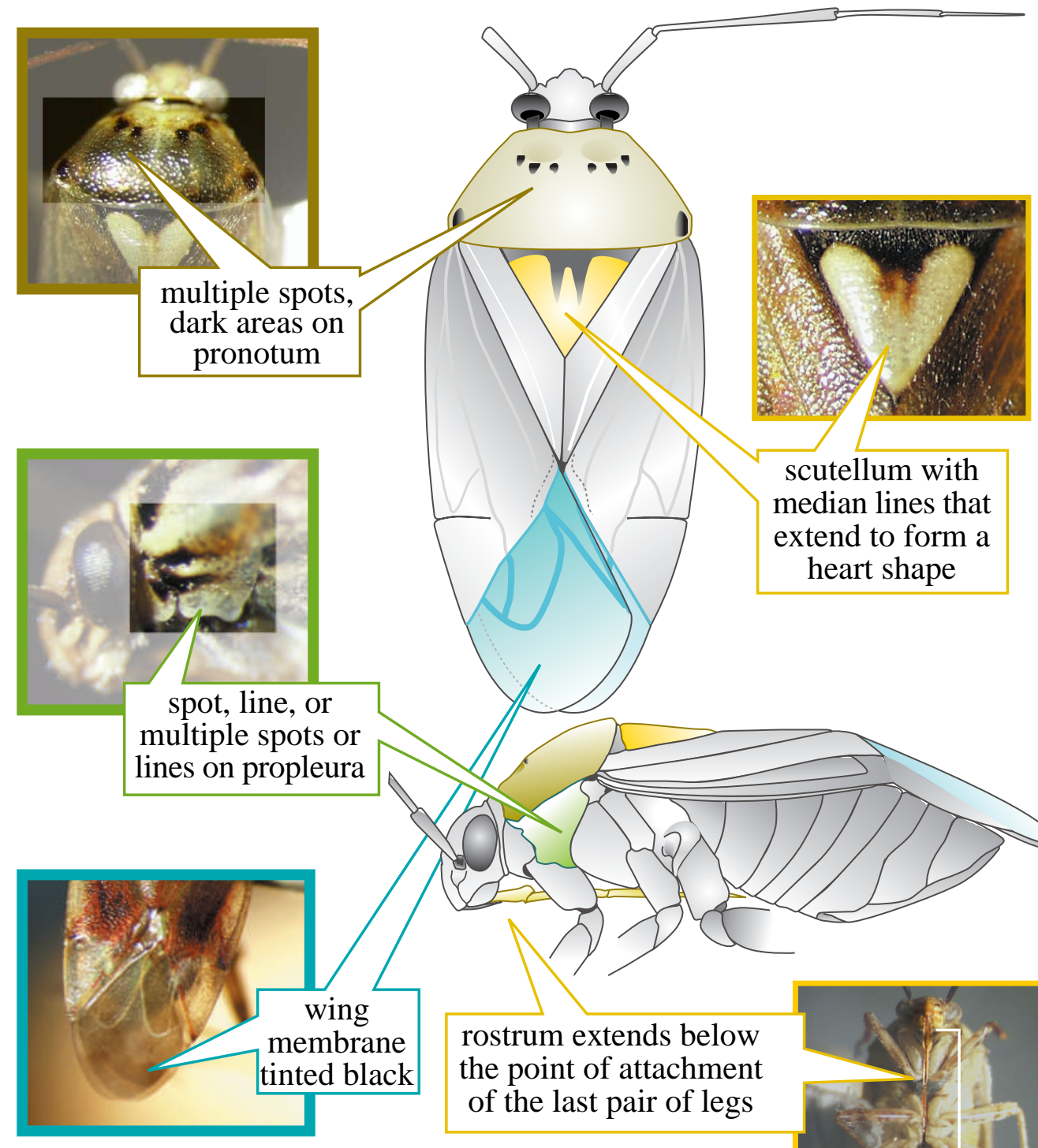

rostrum extends below the point of attachment of the last pair of legs
Shannon C. Mueller, UC Cooperative Extension Farm Advisor, Fresno County Peter B. Goodell, IPM Advisor, UC Statewide IPM Program Charles G. Summers, Dept. of Entomology, UC Davis and Kearney Agricultural Center 


\section{Pale Legume Bug Lygus elisus (Van Duzee)}

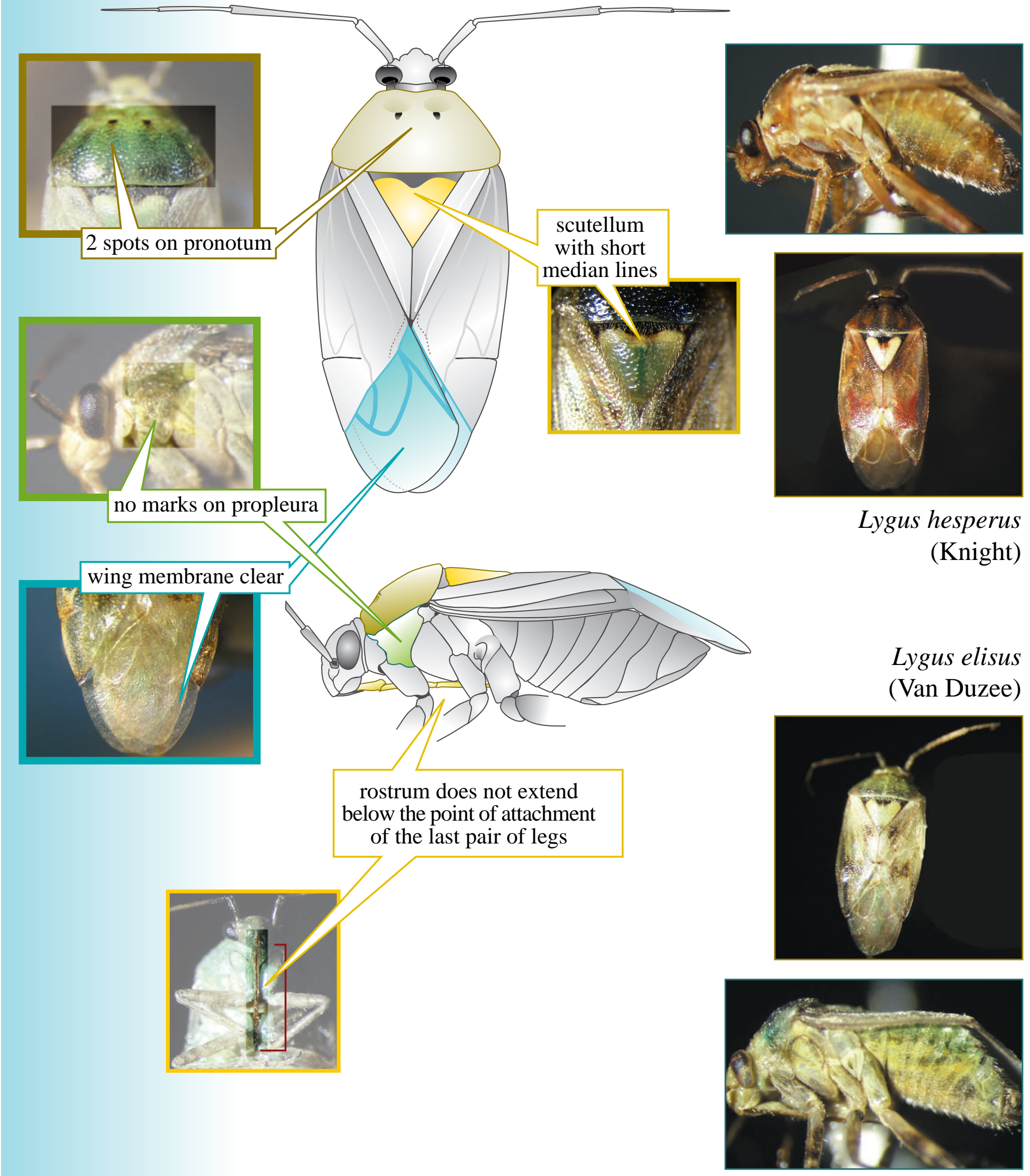




\section{Tarnished Plant Bug Lygus lineolaris (Palisot de Beauvois)} scutellum has both median and lateral lines.

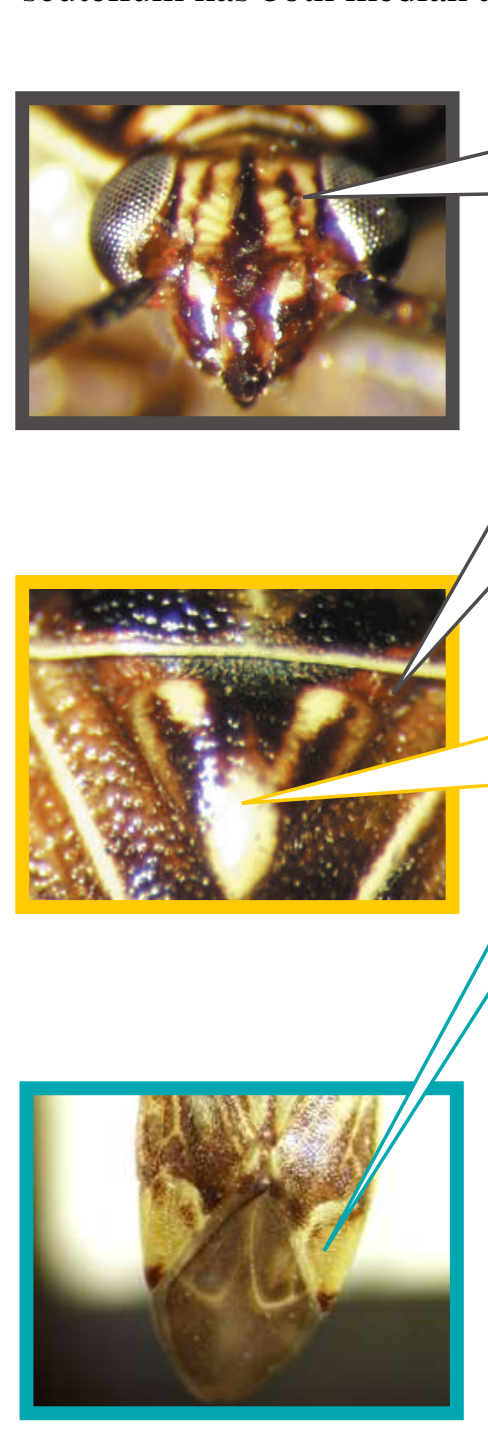

and lateral lines.
frons with
submedian
vittae

and lateral lines.
frons with
submedian
vittae

and lateral lines.
frons with
submedian
vittae

median and lateral lines on the scutellum

pale cuneus with a very large black apex

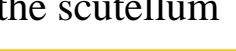
.
black spots, rays, and areas near the callus and base of the pronotum
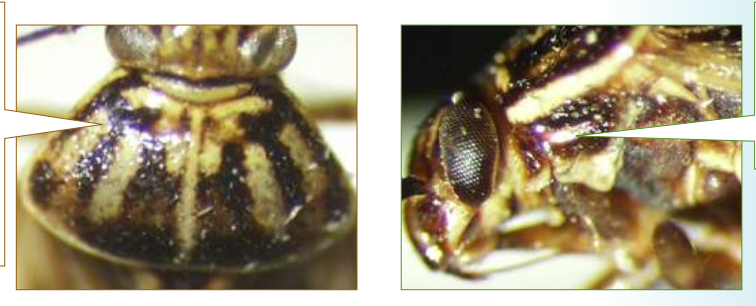

dark lines on the propleura
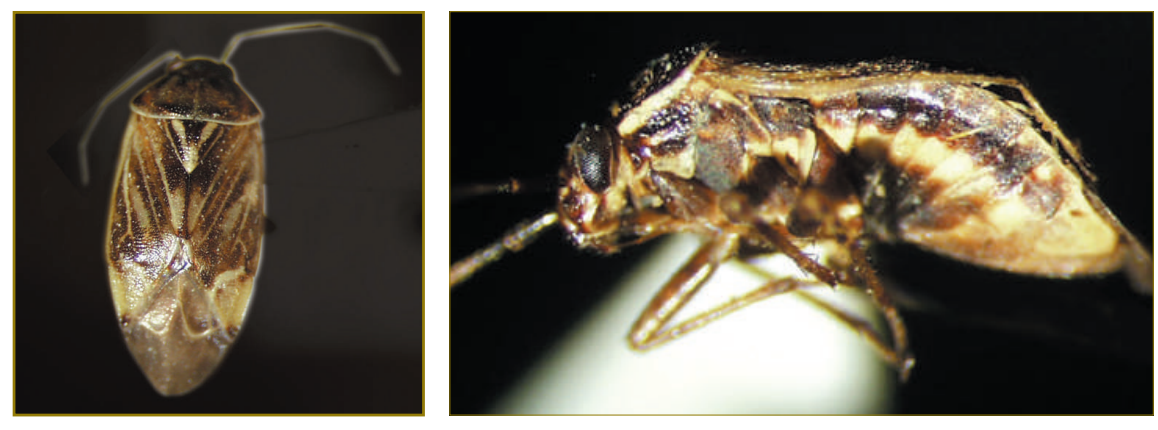

Lygus lineolaris (Palisot de Beauvois) 


\section{Lygus \\ Morphological \\ Characteristics}

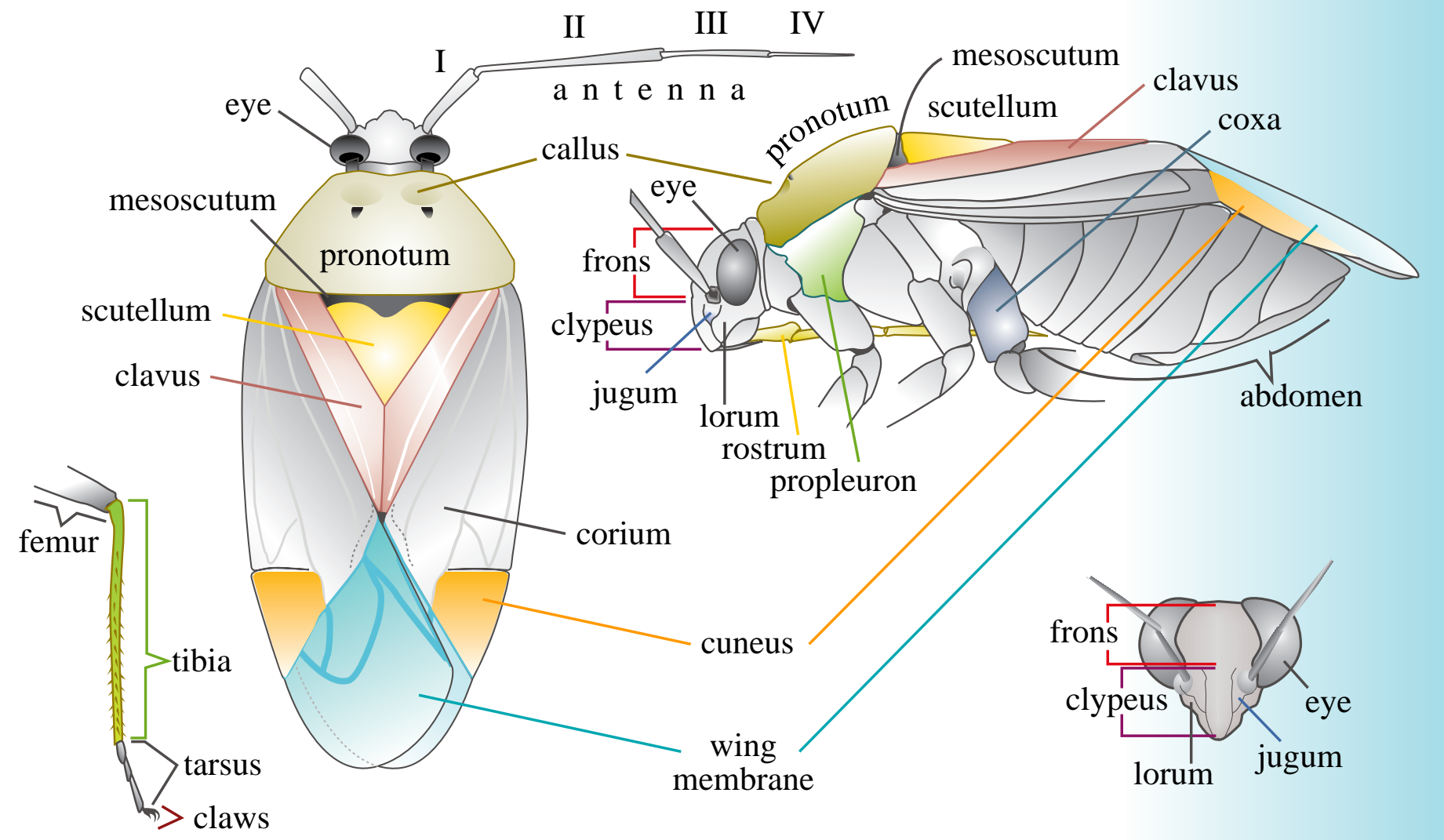

Agriculture $\&$

Natural Resources

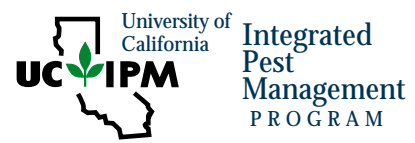

UCM

This publication has been anonymously peer reviewed for technical accuracy by University of California scientists and other qualified professionals. The ANR Associate Editor for Pest Management managed this review process.

(C)2003 by the Regents of the University of California

Division of Agriculture and Natural Resources

All rights reserved.

No part of this publication may be reproduced, stored in a retrieval system, or transmitted, in any form or by any means, electronic, mechanical, photocopying, recording, or otherwise, without the written permission of the publisher and the authors.

University of

Cooperative Extension

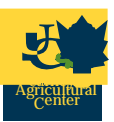

Photos: Shannon Mueller

Graphic design: Gwen Conville

The University of California prohibits discrimination against or harassment of any person employed by or seeking employment with the University on the basis of race, color, national origin, religion, sex, physical or mental disability, medical condition (cancer-related or genetic characteristics), ancestry, marital status, age, sexual orientation, citizenship, or status as a covered veteran (special disabled veteran, Vietnam-era veteran or any other veteran who served on active duty during a war or in a campaign or expedition for which a campaign badge has been authorized). University Policy is intended to be consistent with the provisions of applicable State and Federal laws.

Inquiries regarding the University's nondiscrimination policies may be directed to the Affirmative Action/Staff Personnel Services Director, University of California, Agriculture and Natural Resources, 300 Lakeside Drive, 6th floor, Oakland, CA 94612-3550; (510) 987-0096. For information about ordering this publication, telephone 1-800-994-8849. 